\title{
Estrutura e aplicação da oficina temática: conhecendo a composição dos produtos de limpeza - desenvolvida no âmbito do PIBID/Química da Universidade Federal de Sergipe/Campus Prof. Alberto Carvalho
}

Structure and application of the thematic workshop: Knowing the composition of cleaning products - Developed under the PIBID/Chemistry of the Federal

University of Sergipe/Campus Prof. Alberto Carvalho

\author{
Evanilson Lima Andrade \\ Midiã de Lima Santos Bernardino \\ Luciano Santos \\ João Paulo Mendonça Lima \\ Valéria Priscila de Barros
}

\begin{abstract}
Resumo: Este artigo aborda relatos de uma experiência vivida durante o Programa Institucional de Bolsa de Iniciação à Docência (PIBID) proporcionado pelo Departamento de Química da Universidade Federal de Sergipe (UFS/Campus Prof. Alberto Carvalho). A proposta deste artigo é descrever a aplicação da Oficina temática "Conhecendo a composição dos produtos de limpeza" bem como apresentar indicativos de aprendizagem sobre elemento químico, átomos, moléculas e substâncias, aplicando uma abordagem qualitativa para avaliar o conhecimento dos estudantes. A coleta de dados foi realizada por meio da aplicação de questionário prévio e final. Foi observada a ação dos estudantes relacionadas às práticas contidas na oficina temática. A oficina foi aplicada em quatro horas/aula no mês de outubro de 2019 em uma escola estadual do município de Itabaiana/SE, com nove estudantes do $1^{\circ}$ ano do Ensino Médio. A oficina foi dividida em quatro momentos: análise de rótulos de produtos de limpeza e questionário prévio; explanação do conteúdo e atividade didática; experimento intitulado: "O segredo da reação do bicarbonato de sódio com vinagre"; e questionário final. A partir da interação entre estudantes e bolsistas foram levantadas e sanadas as dúvidas dos estudantes, o que repercutiu diretamente na aprendizagem dos mesmos sobre composição química.
\end{abstract}

Palavras-chave: Oficina temática; Composição química; Produto de limpeza.

Abstract: This research addresses reports of an experience lived during the Institutional Program of Teaching Initiation Scholarship (PIBID) provided by the Department of Chemistry of the Federal University of Sergipe (UFS/Campus Prof. Alberto Carvalho). The purpose of this article is to describe the application of the thematic workshop "Knowing the composition of cleaning products", as well as presenting learning indications about chemical elements, atoms, molecules and substances applying a qualitative approach to assess in students' knowledge. Data collection was performed through the application of a previous and final questionnaire. The action of the students related to the practices contained in the thematic workshop was observed. The workshop was applied in four hours/class in October 2019 in a state school in the municipality of Itabaiana/SE, with nine students from the 1 st year of high school. The workshop was divided into four moments: analysis of labels of cleaning products and previous questionnaire; explanation of content and didactic activity; experiment entitled: "The secret of the reaction of baking soda with vinegar;" and final questionnaire. From the interaction between students and scholarship 
students' doubts were raised and resolved, which had a direct impact on their learning about chemical composition.

Keywords: Thematic workshop. Chemical Composition. Cleaning Product.

\section{Introdução}

O conhecimento é um instrumento que pode mudar as pessoas, pois promove um diferencial na vida do ser humano impulsionando-o para uma melhor qualidade de vida. Para Mizukami (1992), o fenômeno educativo sempre é humano, histórico e multidimensional. Na ação educativa estão presentes as dimensões: humana, técnica, cognitiva, emocional, sociopolítica e cultural. Logo, a educação faz parte da complexidade da vida do ser humano, podendo ser considerada uma ferramenta transformadora, com a função de auxiliar o indivíduo em suas tomadas de decisão.

Falar de educação é falar sobre instituições de ensino, pois estas são responsáveis pela propagação do saber. Tendo como foco o alcance do conhecimento, para, a partir deste, construir um estilo de vida ético e um mundo melhor.

Pensando nisso, os professores da escola básica têm buscado discutir pesquisas sobre ensino e aprendizagem a fim de melhorar o entendimento dos conteúdos ensinados. Existem diferentes formas de ensinar os conceitos químicos; uma delas é por meio da aplicação de oficinas temáticas.

A oficina temática é uma ferramenta importante na aprendizagem, pois leva em consideração os fatos pertinentes do dia a dia dos estudantes. Assim, a oficina é produzida na busca de relacionar estes fatos com conteúdos de química que os explicam (MARCONDES, 2008). Por muito tempo o conhecimento científico mostrou-se distante da realidade das pessoas, pois a maneira como o saber era, ou ainda é, exposto, focava apenas na transmissão dos conteúdos.

De acordo com Freire (1987), o ensino tradicional associa-se a uma visão bancária, em que o conhecimento é depositado. Não caberia ao estudante a descoberta do aprendizado, ou de experiências novas ligadas ao contexto do saber, mas, ele apenas deveria aceitar como conhecimento, aquilo 
que lhe fosse transmitido pelo professor, o qual era reconhecido como autoritário e capacitado para transmiti-lo. Sendo assim, afirma-se que:

\begin{abstract}
Não é de estranhar, pois, que nessa visão "bancária" da educação os homens sejam vistos como seres da adaptação, do ajustamento. Quanto mais se exercitem os educandos no arquivamento dos depósitos que Ihe são feitos, tanto menos desenvolverão em si a consciência crítica de que resultaria a sua inserção no mundo, como transformadores dele (FREIRE, 1987, p. 34).
\end{abstract}

Ao longo dos anos, a ideia de que o conhecimento não deveria ser depositado no estudante e sim construído, foi ganhando espaço. Para o estudante desenvolver uma visão crítica, tornando-se capaz de ser um agente de transformação do mundo, em sala de aula e fora dela, ele deveria participar do processo de construção do saber com a mediação do professor.

Como assevera Freire (1996), é preciso compreender que ensinar não se resume a uma transferência de conhecimentos; ensinar é uma via de mão dupla, na qual tanto o estudante quanto o professor são beneficiados, pois há uma troca de conhecimentos e experiências.

Esse entendimento, que tanto o professor quanto o estudante aprendem juntos, é libertador, pois permite explanar diferentes tipos de conteúdo que abrangem temas sociais, relativos ao que é comum aos estudantes.

Para explorar essas temáticas, a realização de oficinas direcionadas a um determinado tema presente no dia a dia do estudante, tem se mostrado um mecanismo eficiente no aprendizado de química, pois, os conhecimentos que os estudantes possuem não são dispensados, mas, sim, são de grande valia para o aprendizado (MARCONDES, 2008).

De acordo com Marcondes (2008), a oficina temática utiliza a vivência dos estudantes e dos fatos do dia a dia, para favorecer novas aprendizagens. O uso de temas relevantes provoca uma contextualização do conhecimento, permitindo a eles a melhoria de sua aprendizagem, enquanto o professor acompanha esse desenvolvimento.

A contextualização do conteúdo permite que os estudantes compreendam melhor sobre a química, com o intuito de se tornassem cidadãos mais preparados para exercerem a cidadania, sendo um progresso, pois, dessa 
forma, contribuem com o desenvolvimento do ambiente em que vivem. Uma discussão aprofundada sobre temas socialmente relevantes provoca um exercício do pensar, o qual traz um impacto sobre o indivíduo a ponto de melhorar suas atitudes como cidadão (CACHAPUZ; PRAIA; JORGE, 2004).

Não é simples o ensinar química por meio de temas, pois o ensino, a partir de temáticas sociais, precisa ser bem-estruturado, havendo uma paridade entre o viés humano, social e os conteúdos químicos. Dessa forma, busca-se desenvolver no estudante o pensamento crítico, tornando-o apto para enfrentar e resolver problemas de qualquer âmbito à luz do conhecimento científico (MARCONDES, 2008).

Levando em consideração a importância da explanação do conteúdo químico por meio de temas, foi desenvolvida, no âmbito do Programa Institucional de Bolsa de Iniciação à Docência (PIBID), do Departamento de Química da Universidade Federal de Sergipe (UFS/Campus Prof. Alberto Carvalho), a oficina temática "Conhecendo a composição dos produtos de limpeza". A proposta teve como objetivo a compreensão das diferenciações dos conceitos de elemento químico, átomos, moléculas e substâncias simples e compostas.

Ensinar a composição química dos produtos de limpeza é uma possibilidade de mostrar como a química está inserida no dia a dia. Além do mais, os efeitos da má utilização dos produtos de limpeza podem ser explorados, problematizando os prejuízos à saúde humana.

O objetivo deste trabalho foi demonstrar os resultados obtidos com a realização da oficina temática "Conhecendo a composição dos produtos de limpeza", sendo descrita a abordagem que foi usada e a metodologia aplicada.

\section{Metodologia}

A presente pesquisa está centrada em uma abordagem qualitativa, a qual consiste em uma compreensão da ciência por meio de interações sociais, posto que é levado em questão o contexto sociocultural e o espaço onde a pesquisa é realizada. Comumente ela é feita em um ambiente natural para a coleta de dados, tendo o pesquisador como seu instrumento (LÜDKE; ANDRÉ, 
1986). O processo da análise dos resultados obtidos ocorre de maneira indutiva. Tendo em vista isso, os dados recolhidos nos questionários são descritivos, uma vez que estes foram interpretados pelos próprios autores da oficina temática, que também buscaram, a partir desta abordagem, investigar o conhecimento construído pelos estudantes sobre átomos, moléculas e substâncias.

A oficina temática intitulada "Conhecendo a composição dos produtos de limpeza" foi aplicada em quatro horas/aula no mês de outubro de 2019 em uma escola estadual do município de Itabaiana/SE, com nove estudantes do $1^{\circ}$ ano do Ensino Médio.

Para a realização da oficina utilizou-se alguns recursos, como projetor, notebook, quadro branco, pincel, papel A4, caneta, vidraria de laboratório (béquer, erlenmeyer, funil), colher, balão de festa, bicarbonato de sódio e vinagre.

A oficina foi estruturada em quatro momentos. Primeiramente foram apresentados aos estudantes diferentes rótulos de produtos de limpeza para leitura da composição química. Após a realização desta etapa, foi aplicado o questionário prévio com as seguintes perguntas: 1) Você costuma ler os rótulos dos produtos de limpeza? Explique sua resposta; 2) Você utiliza este produto do rótulo que recebeu? 3) Com qual finalidade você utiliza? 4) Você poderia citar o nome de elementos químicos presentes neste rótulo? 5) Para você, o que é substância?

Essas perguntas tinham como proposta saber se os estudantes faziam o uso destes materiais em seu dia a dia e se eles apresentavam alguma noção acerca da composição química destes. A partir da análise geral das respostas, todos os estudantes receberam um código de identificação do tipo "1D1, 1D2, ...", garantindo, assim, o anonimato dos nove estudantes. O questionário prévio foi utilizado como instrumento para a coleta de dados da pesquisa.

No segundo momento foi realizada uma atividade didática denominada "A química nos produtos de limpeza." Esta atividade foi feita com Espuma Vinílica Acetinada (E.V.A), em que cada esfera representava um átomo e/ou elemento químico (Figura 1). 
Nesta atividade os estudantes deveriam unir as quantidades e os átomos a fim de montar a composição de diferentes substâncias químicas presentes nos produtos de limpeza conhecidos por eles. Os conceitos químicos foram revisados antes da atividade, o que foi realizado por meio de explanação no quadro utilizando figuras para a representação dos átomos, permitindo a eles uma melhor compreensão.

Figura 1. Esferas de E.V.A representando átomo e/ou elemento químico utilizado na atividade didática

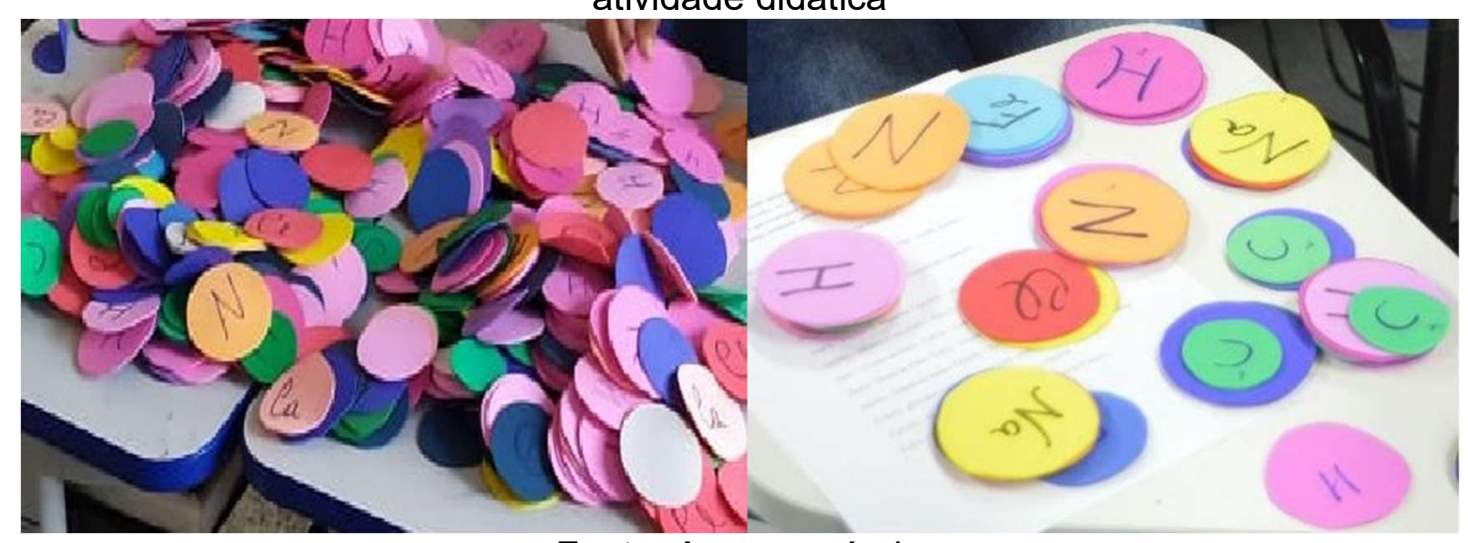

Fonte: Acervo próprio

O terceiro momento consistiu na realização do experimento "O segredo da reação do bicarbonato de sódio com vinagre", que teve como objetivo discutir a composição química das substâncias envolvidas e a reação química entre elas (Figura 2).

Figura 2. Experimento da reação química do bicarbonato de sódio com vinagre

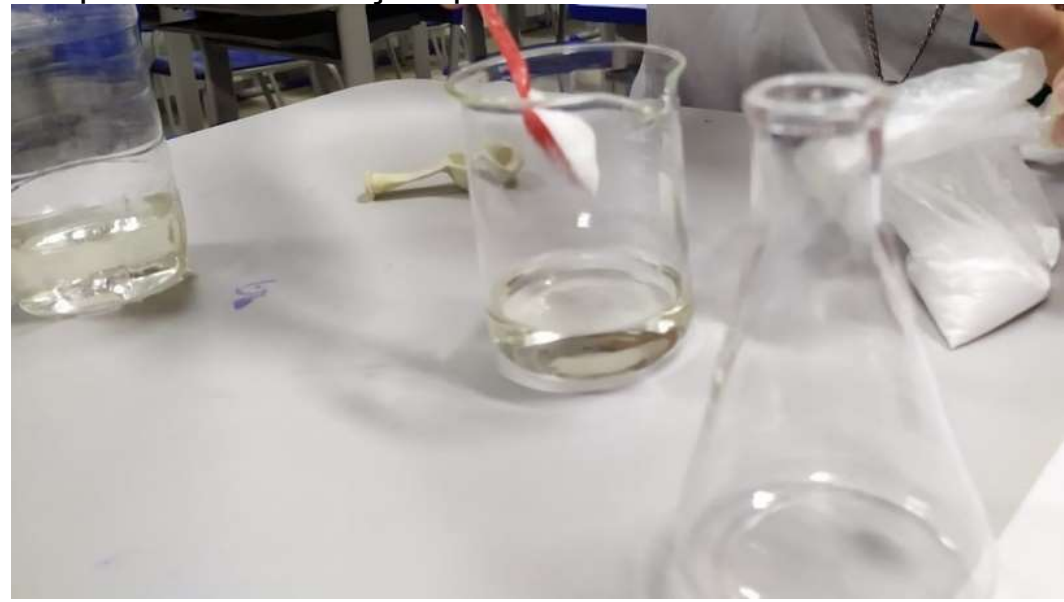

Fonte: Acervo próprio. 
No terceiro momento, para a realização do experimento a classe foi dividida em dois grupos e, então, foi entregue um roteiro, ressaltando a importância da atenção no manuseio das vidrarias, além de não cheirar e/ou ingerir nenhuma das substâncias empregadas no experimento.

No quarto e último momento houve a aplicação de um questionário final e individual com três questões, com o intuito de avaliar o aprendizado a partir da oficina. Buscou-se relacionar as diferenças entre elemento químico, átomo, molécula e substâncias simples e compostas. Os autores da oficina temática analisaram os dados obtidos por meio da comparação das respostas dos estudantes no questionário prévio com as obtidas no questionário final. As perguntas do experimento também foram usadas para relatar se houve indícios de aprendizagem por parte dos estudantes participantes.

\section{Resultados e discussão}

\section{Análise do questionário prévio}

Sabendo que cada estudante possui um conhecimento, foi aplicado um questionário prévio para verificação de suas ideias sobre conceitos e temas presentes na oficina. Três questões foram selecionadas para a análise.

\section{Da análise da questão: Você costuma ler os rótulos dos produtos de limpeza? Explique sua resposta}

Na primeira pergunta, dos nove estudantes seis responderam que não liam os rótulos, pois não tinham curiosidade, como foi verificado na resposta do estudante 1D6: "Não, pois não tenho muita curiosidade em conhecer seus componentes". Esta resposta, como a da maioria, mostra a necessidade de conscientizar os estudantes da importância de analisar os rótulos dos produtos de limpeza, lendo as especificações, advertências e modo de uso.

A conscientização acarreta tomadas de decisão corretas, considerando que "Hoje, há uma convicção de que a Ciência que ensinamos deve servir para que nossas alunas e estudantes se transformem em mulheres e homens capazes de exercerem uma cidadania cada vez mais crítica [...]" (CHASSOT; 
VENQUIARUTO; DALLAGO, 2005), pois o uso incorreto de determinados produtos pode ocasionar alergias, problemas respiratórios ou intoxicações (SANTOS et al., 2011).

Três estudantes responderam sim, como o estudante "1D8 - Sim, pois é muito importante para saber o que podemos fazer e como usar". A utilização dos rótulos dos produtos de limpeza, além de contribuir com a compreensão do conteúdo químico, desperta o senso crítico, a interpretação, ampliando os níveis de leitura e escrita. A química, por possuir vários princípios e leis, resulta em uma difícil compreensão dos estudantes, os quais, em boa parte, afastamse e perdem o interesse pela disciplina. Assim, aqueles que buscam a leitura e o entendimento do meio que o cercam, tornam-se mais conscientes (SOETHE; LUCA, 2018).

\section{Da análise da questão: Você poderia citar o nome de elementos químicos presentes neste rótulo?}

Para responder essa pergunta foram distribuídos aos estudantes diversos rótulos de produtos de limpezas, tais como sabonetes, limpa alumínio, água sanitária, creme dental, água e vinagre.

$\mathrm{Na}$ quarta questão buscou-se perceber se os estudantes reconheciam os elementos químicos que faziam parte da composição química dos produtos de limpeza, levando em consideração que, eles conheciam os rótulos que the foram entregues. Um elemento químico é formado por um conjunto de átomos idênticos. Assim, átomos diferentes formam elementos químicos distintos. Por exemplo, o elemento químico Hidrogênio é formado por um conjunto de átomos de Hidrogênio (BROWN; LEMAY; BURSTEN, 2005).

Notou-se que os nove estudantes apenas colocaram a composição dos produtos que estavam indicados no rótulo, como mostra a resposta de 1D1, que analisou o rótulo de um creme dental e escreveu "sodium, celulose, calcium carbonato, etc.". Esta resposta foi transcrita pelo estudante da mesma maneira que estava no rótulo. O mesmo foi feito pelo restante dos estudantes com seus respectivos rótulos, revelando assim, que, inicialmente eles não 
conseguiam distinguir a diferença de composição química para algo mais específico, como elemento químico.

\section{Da análise da questão: Para você, o que é substância?}

Nesta pergunta buscou-se identificar se os estudantes compreendiam o conceito de substância. Quatro estudantes não responderam, e três apresentaram respostas diferentes do que é proposto na literatura, como mostra a resposta do estudante 1D1: "São as coisas que vêm no rótulo de um produto, são as substâncias químicas". Essa pode ser considerada uma resposta incoerente, pois a substância química é formada por uma composição constante de átomos do mesmo ou de diferentes elementos químicos que tenham propriedades físicas e químicas definidas (BROWN; LEMAY; BURSTEN, 2005).

O estudante 1D4 respondeu de forma coerente: "É o agrupamento de átomos iguais ou diferentes"; já o 1D9 respondeu referindo-se à composição da substância: "Substância pode ser simples ou compostas, são as simples as que têm apenas elemento químico igual".

Segundo Silva e Amaral (2016), substância é um dos principais conceitos dentro da química, o que permite a compreensão de vários fenômenos, além de estar presente no dia a dia.

\section{Discussão do conteúdo e atividade didática "A química nos produtos de limpeza}

No decorrer da oficina houve a discussão e aprofundamento do conteúdo. Essa explanação tinha como base a explicação do conteúdo sobre elemento químico, átomo de Dalton, molécula e substância. De acordo com Oki (2002), esses conceitos norteiam e impulsionam as transformações da ciência química por serem básicos.

Esses conceitos foram mostrados e relacionados com os componentes de alguns produtos de limpeza no momento da aplicação do questionário prévio. Durante a explanação do conteúdo, os estudantes, em sua maioria, sentiram bastante dificuldade na diferenciação entre elemento químico, que é o 
conjunto de átomos com mesmo número atômico, e moléculas, que é a união de dois ou mais átomos ligados entre si. Com relação ao conceito de átomo, por este ser este mais simples, os estudantes compreenderam melhor. Com isso, essas dúvidas foram sendo sanadas com o auxílio da atividade "A química nos produtos de limpeza", a qual consistiu em fazer com que os estudantes montassem a composição química de diferentes produtos de limpeza, tendo de levar em consideração a quantidade de átomos presentes na composição de cada um.

No meio educacional a disciplina de química é tratada como um "bichopapão", sendo determinada como uma matéria abstrata, e, com isso, a inserção de novas metodologias acrescenta muito para o ensino de química. Cada grupo tinha uma folha, a qual continha uma lista com a fórmula molecular de várias substâncias presentes nos produtos de limpeza. A atividade utilizou bolas de emborrachado denominadas de átomos. Com isso, os estudantes, em grupo, identificavam quais elementos químicos eram necessários para formar determinada substância. No decorrer da atividade, eles perguntavam sobre alguns elementos químicos, dos quais não compreendiam seu símbolo, e sobre o índice das substâncias.

\section{Análise do experimento}

A turma foi dividida em equipes de cinco pessoas, tendo cada grupo recebido um roteiro do experimento, o qual foi lido pelos bolsistas juntamente com os estudantes. O experimento, que foi realizado pelos estudantes sob a orientação dos bolsistas, sendo denominado de "O segredo da reação do bicarbonato de sódio e vinagre", consistiu em uma reação química que utilizou bicarbonato de sódio e vinagre como reagentes, gerando acetato de sódio, água e gás carbônico como produtos. A partir das substâncias foi apresentada a diferença de suas composições, como é verificada na reação a seguir:

$$
\mathrm{NaHCO}_{3}(\mathrm{~s})+\mathrm{CH}_{3} \mathrm{COOH}(\mathrm{aq}) \rightarrow \mathrm{CH}_{3} \mathrm{COONa}_{(\mathrm{aq})}+\mathrm{H}_{2} \mathrm{O}_{(\mathrm{l})}+\mathrm{CO}_{2}(\mathrm{~g})
$$

Com esse experimento o significado de substância química foi consolidado, pois, a partir da reação, houve a formação de novas substâncias (BROWN; LEMAY; BURSTEN, 2005). 
A escolha deste experimento ocorreu por ele ser interativo, utilizando reagentes que também são usados como produtos de limpeza, e, sendo seus produtos utilizados de forma correta, não ocasionam danos à saúde. Além disso, a escolha priorizou a confecção do experimento dentro da sala aula sem precisar de equipamentos laboratoriais complexos. Por ter produtos não nocivos à saúde, foi ensinado aos estudantes que o uso incorreto de produtos de limpeza, principalmente numa mistura inadequada, pode gerar substâncias que sejam prejudiciais à saúde, com liberação de gases tóxicos. Após a realização do experimento, os estudantes responderam questionamentos que demonstraram que houve um índice de aprendizagem por parte deles em relação à formação de uma nova substância a partir da mistura de duas, entendendo que o produto originado possui uma composição diferente da substância inicial, isto é, tendo suas próprias características.

\section{Questionário final}

Com a aplicação do questionário final foi possível avaliar indicativos de aprendizagem por parte dos estudantes, mediante a aplicação da oficina temática. O questionário era composto por três questões, as quais tinham como intuito compreender se os estudantes conseguiram entender a diferença entre átomo, elemento químico, molécula e substância.

$\mathrm{Da}$ análise da questão: Segundo o que já foi explicado, qual o conceito do átomo representado pela teoria de Dalton?

De acordo com a análise, observou-se que os estudantes já possuíam uma noção coerente sobre o átomo de Dalton, que considera o átomo como uma partícula indestrutível, indivisível, maciça e esférica, representativa do elemento químico. Oito dos noves estudantes responderam de forma coerente, como o estudante 1D3: "Indivisível, indestrutível, impenetrável, maciça e esférica, aparentemente comparado a uma bola de bilhar". 
Da análise da questão: Segundo o modelo atômico de Dalton, observe o sistema a seguir:

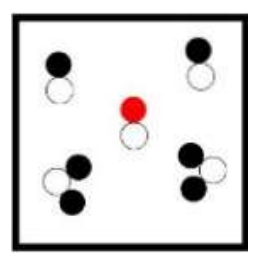

a) Quantos tipos de elementos químicos e quantos átomos estão presentes na imagem acima?

b) Agora, qual a quantidade de moléculas e substâncias, presentes na imagem acima?

Cada círculo da imagem representa um átomo; as cores representam átomos pertencentes a diferentes elementos químicos, e cada união entre átomos representa as moléculas que compõem a formação das substâncias. $A$ partir das análises das respostas do item a) da questão, pode-se observar que 7 dos 9 estudantes a resolveram de forma coerente (sendo a resposta correta: 3 elementos químicos e 12 átomos) e 2 estudantes responderam de forma incoerente.

Os estudantes utilizaram formas diferentes para expressar as suas respostas, como o 1D3: "3 tipos de elemento químico, 6 átomos pretos, 5 átomos brancos e 1 átomo vermelho, no total de 12 átomos". Este estudante especificou detalhadamente a resposta; já o estudante 1D8, com "A = 12, E.Q = 3", respondeu de forma mais breve, que também está correta, pois na questão não foi solicitado para especificar os átomos.

Referente ao item b) da questão, dois estudantes responderam corretamente, sendo cinco moléculas e três substâncias. Os outros seis estudantes acertaram a quantidade correta de moléculas. Os resultados mostram que a maioria dos estudantes não consegue identificar o que é substância e molécula, principalmente por ter sido abordado um modelo diferente das questões. Mesmo sendo conceitos mais complexos, e o conteúdo apresentado com recursos diferentes, como a imagem e bolinhas de E.V.A, ainda assim alguns estudantes não conseguem atrelar os dois modos e não compreendem o mesmo significado. 


\section{Da análise da questão: Observando o sistema a seguir:}

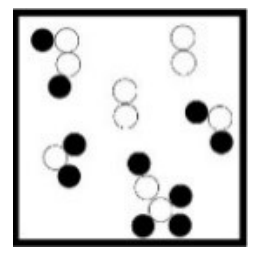

a) Qual a quantidade de moléculas e a composição de cada uma existente nesse sistema?

A última questão teve como finalidade identificar, por parte dos estudantes, moléculas e sua composição, usando cores diferentes para cada elemento químico. Nessa questão pode-se identificar que oito estudantes responderam corretamente por meio de duas formas: a primeira, que mostrava a composição referente à sua classificação em simples ou composta, foi respondida por quatro estudantes e de modo semelhante pelo estudante 1D1: "6 moléculas são simples e compostas"; e a segunda, que mostrava a composição referente a quantidades de átomos e cada tipo, foi assim respondida pelo estudante 1D6: 6 moléculas, duas moléculas $=2$ brancas, 1 elemento químico; duas moléculas $=1$ branco e dois pretas, 2 elementos químicos; uma molécula $=2$ brancas e 2 pretas; 2 elementos químicos; uma molécula $=4$ pretas e 2 brancas, 2 elementos químicos". Somente um estudante respondeu incorretamente, mostrando que, diferentemente da questão anterior, o aproveitamento dessa foi alto e que o acréscimo de um tipo de elemento químico na questão anterior pode ter sido um fator gerador de erro.

\section{Conclusão}

Conclui-se que a oficina "Conhecendo a composição dos produtos de limpeza" contribuiu no aprendizado dos estudantes a partir da leitura de rótulos, e na compreensão dos conceitos químicos de elemento químico, átomo, molécula e substância. Ainda, esta oficina contribuiu para a formação científica dos estudantes e para a inserção do conhecimento cotidiano que muitos não conseguiam entender. A utilização da atividade didática "A química nos 
produtos de limpeza" gerou nos estudantes uma euforia e rendeu várias perguntas para tentar compreender o conteúdo com esse recurso.

A interação com os estudantes ocorreu de forma diferente da tradicional, na qual eles são colocados em círculos e, posteriormente, em grupos. Pela análise dos dados, o resultado da oficina foi satisfatório, verificando-se que a maioria dos estudantes conseguiu responder de forma coerente às perguntas propostas. Com a boa interação entre estudante e professor, foram levantadas várias dúvidas pelos estudantes, as quais foram sanadas.

\section{Agradecimentos}

Ao Programa Institucional de Bolsa de Iniciação à DocênciaPIBID/CAPES pelo apoio financeiro e concessão das bolsas, aos alunos, aos professores supervisores e às escolas participantes, aos orientadores do PIBID/CAPES/UFS/Química/Campus de Itabaiana e aos colegas bolsistas pela partilha de ideias.

\section{Referências}

BROWN, T. L.; LEMAY, H. L.; BURSTEN, B. E. Química: a ciência central. 9. ed. São Paulo: Pearson, 2005.

CACHAPUZ, A. F.; PRAIA, J. F.; JORGE, M. P. Da educação em ciência às orientações para o ensino das ciências: um repensar epistemológico. Ciência \& Educação, v. 10, n. 3, p. 363-381, 2004.

CHASSOT, A.; VENQUIARUTO, L. D.; DALLAGO, R. M. De olho nos rótulos: compreendendo a unidade caloria. Química Nova na Escola, n. 21, maio 2005.

FREIRE, P. Pedagogia da autonomia: saberes necessários à prática educativa. 25. ed. São Paulo: Paz e Terra, 1996.

FREIRE, P. Pedagogia do oprimido. 17. ed. Rio de Janeiro: Paz e Terra, 1987.

LÜDKE, M; ANDRÉ, M.E.D.A. Pesquisa em Educação: Abordagens Qualitativas. São Paulo: EPU, 1986.

MARCONDES, M. E. R. Proposições metodológicas para o ensino de química: oficinas temáticas para a aprendizagem da ciência e o desenvolvimento da cidadania. Em Extensão, Uberlândia, v. 7, p. 67-77, 2008. 
MIZUKAMI, M. G. N. Ensino: as abordagens do processo. 1. ed. São Paulo: E.P.U., 1992.

OKI, M. C. M. O conceito de elemento químico: da antiguidade à modernidade. Química Nova na Escola, n. 16, nov. 2002.

SANTOS, J. A. T.; SELEGHIM, M. R.; MARANGONI, S. R.; GONÇALVES, A. M.; BALLANI, T. S. L.; OLIVEIRA, M. L. F. Gravidade de intoxicações por saneantes clandestinos. Texto \& Contexto - Enfermagem, v. 20, p. 247-254, 2011.

SILVA, J. R. R. T.; AMARAL, E. M. R. Concepções sobre substância: relações entre contextos de origem e possíveis atribuições de sentidos. Química Nova na Escola, v. 38, n. 1, p. 70-78, fev. 2016.

SOETHE, A. A.; LUCA, A. G. Problematizando o ensino de química por meio da leitura de embalagens/rótulos: uma proposta para o segundo ano do Ensino Médio. Revista de Estudos e Pesquisas sobre Ensino Tecnológico Educitec, v. 4, n. 9, p. 222-235, dez. 2018.

\section{Sobre os autores}

\section{Evanilson Lima Andrade}

evanilson10sp@outlook.com

Discente do curso de Química, Universidade Federal de Sergipe-UFS/Campus Prof. Alberto Carvalho. Bolsista do Programa PIBID no período de agosto de 2018 a janeiro de 2020.

\section{Midiã de Lima Santos Bernardino}

midiiejesus@outlook.com

Discente do curso de Química, Universidade Federal de Sergipe-UFS/Campus Prof. Alberto Carvalho. Bolsista do Programa PIBID no período de agosto de 2018 a janeiro de 2020.

\section{Luciano Santos}

luciano.quimica@hotmail.com

Professor da Educação Básica do Estado de Sergipe. Mestre em Química pela Universidade Federal de Sergipe-UFS. Supervisor no programa PIBID.

\section{João Paulo Mendonça Lima}

jpufs@hotmail.com

Professor-adjunto do Departamento de Química, Universidade Federal de Sergipe-UFS/Campus Prof. Alberto Carvalho. Doutorado em Educação pela UFS. Pesquisador do Programa de Pós-Graduação em Ciências Naturais (PPGCN-UFS) na área de Ensino em Ciências. Coordenador de área do PIBID. 


\section{Valéria Priscila de Barros}

vpbarros@yahoo.com

https://orcid.org/0000-0003-3272-5076

Professora-adjunta do Departamento de Química, Universidade Federal de Sergipe-UFS/Campus Prof. Alberto Carvalho. Pós-doutorado em produtos naturais pela Universidade de São Paulo-USP. Pesquisadora do Programa de Pós-Graduação em Ciências Naturais (PPGCN-UFS) na área de Saúde e Meio Ambiente. 